\title{
THE STRUCTURE AND HEAT DEPENDENCE OF SILICON SPREADING RESISTANCE TEMPERATURE SENSORS
}

\author{
GY. PÁSZTOR, J. BERKECZ, N.M. FICZA \\ MEV Microelectronics Co., P.O.B. 21., Budapest, Hungary. H-1325 \\ (Received Mry 31, 1988; in final form September 30, 1988)
}

The construction method of the sensor SRTS with two roundshaped diffusion layers is given The effect of geometry on the sensor resistance is determined theoretically. An approximating method is given to determine the temperature dependence of the sensor in the range of $200 \mathrm{~K}<\mathrm{T}<400 \mathrm{~K}$. Calculated results are compared to measurements.

\section{INTRODUCTION}

The principle of spreading resistance leads to a very efficient silicon temperature sensor structure (SRTS). The advantages of this structure are twofold. A given resistance value can be easily verified by adjusting the contact diameter, and the structure can be realized by using the well-known planar technology. The resistance temperature dependence of this element close to a temperature $T_{o}$ can be described as $R=R_{o}\left[1+\alpha\left(T-T_{o}\right)\right]$ where $\alpha$ is the temperature coefficient, (TC). In the ambient temperature range the value of $\alpha$ is defined mainly by the heat dependence of electron mobility $\mu_{n}$, which varies only slightly with the change of donor concentration $N_{D}$. Therefore a precisely determined TC value can be easily realised. Experiments with this structure are widely discussed in the literature. ${ }^{1-3}$ The effect of geometry and the doping concentration is examined experimentally. However a detailed theoretical examination has not been made yet. Therefore an approximating method has been worked out to construct SRTS structures. Their temperature and doping concentration dependences have also been calculated in the temperature range $200-400 \mathrm{~K}$ and doping concentration range $2 \cdot 10^{15}>\mathrm{N}_{\mathrm{D}}>8 \cdot 10^{14} \mathrm{~cm}^{-3}$.

\section{THE GEOMETRY DESIGN}

The cross section of the SRTS is illustrated in Fig. 1. The metal electrodes A, B serve as ohmic contacts to the diffused $\mathrm{n}^{+}$layer. This layer has 


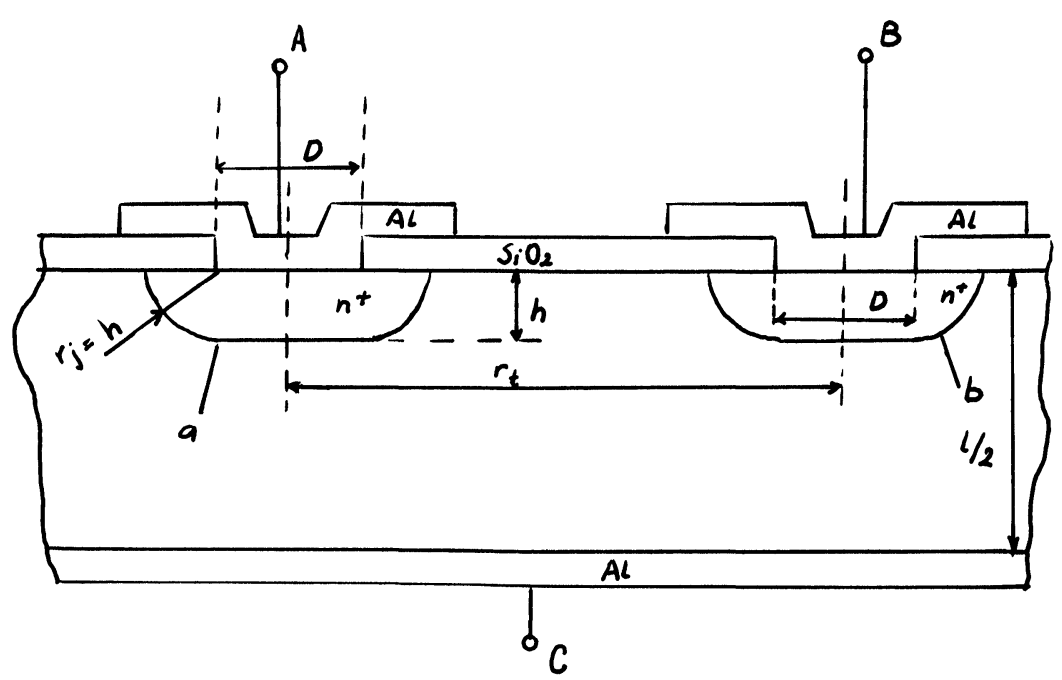

FIGURE 1 The cross section of the SRTS

sufficiently low sheet resistance, so the $\mathrm{n}-\mathrm{n}^{+}$junction can be considered as an equipotential. The metallisation on the back surface of the chip $\mathrm{C}$ gives also an ohmic contact. The diffusion layers a, b represent a symmetrical structure. Having left the $\mathrm{n}^{+}$layer the current spreads over the $\mathrm{n}$ substrate. In order to compute the resistance of the circuit A,B the distribution function of the electrical field has to be known. An approximate solution of the problem can be achieved by replacing the structure of Fig. 1 by an other one, which can be seen in Fig. 2 . In this case the equipotential $\mathrm{n}-\mathrm{n}^{+}$junction are considered to be hemispheres. The spherical radius $r_{o}$ has a value at which the surface of the hemisphere equals to that of the $\mathrm{n}-\mathrm{n}^{+}$junction in Fig. 1. The metallisation $\mathrm{c}$ can be found in the median plane of Fig. 2. The distance of the spherical centres $(\ell)$ is double the thickness of the semiconductor chip. Considering the charges $\mathrm{Q}^{+}$and $\mathrm{Q}^{-}$ in the spherical centres, as it can be seen in Fig. 3. $\left(\mathrm{Q}^{+}=\mathrm{Q}^{-}\right)$, the potential value in a point $P$ can be calculated from equation 1.1:

$\mathrm{Up}=\frac{\mathrm{Q}}{4 \pi \varepsilon_{\mathrm{si}}}\left(\frac{1}{\mathrm{r}^{+}}-\frac{1}{\mathrm{r}^{-}}\right)$

where $\varepsilon_{\mathrm{si}}$ is the dielectric constant of silicon, and $\mathrm{r}^{+}, \mathrm{r}^{-}$are the distances 


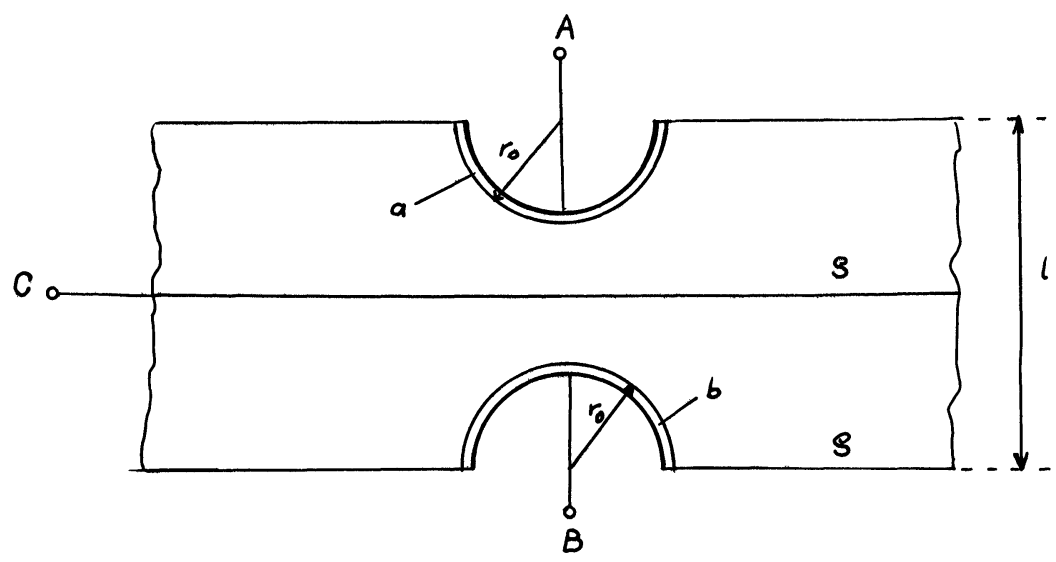

FIGURE 2 The cross section of the approximate structute

of $\mathrm{P}$ from $\mathrm{Q}^{+}$and $\mathrm{Q}^{-}$, respectively. The current density, $\mathrm{j}$ can be calculated simply by the aid of the electrical field $\mathrm{E}$.

$j=\rho^{-1} E$

Strictly speaking, the shape of the eqipotential surface around $Q$ deviates from a sphere. The degree of deviation can be estimated by comparing the lengths of radii $r_{o}, r_{1}$ of two equipotential points $P_{o}, P_{1}$. The deviation can be characterised by $\Delta r=r_{1}-r_{o}$.

The relative deviation is given by:

$\frac{\Delta \mathrm{r}}{\mathrm{r}} \cong \mathrm{r}_{\mathrm{o}}\left(\frac{1}{\mathrm{r}_{\mathrm{o}}}-\frac{1}{\mathrm{r}_{1}}\right) \cong \mathrm{r}_{0}^{2} / \ell^{2}$

If the constraint $r_{o} \ll 1$ is valid, the equipotential surface can be considered to be a sphere, with a negligible error. This means that for the calculation of field strength the nearer charge has to be considered only:

$\mathrm{E}_{\mathrm{ro}}=-\left.\frac{\partial \mathrm{U}}{\partial \mathrm{r}}\right|_{\mathrm{r}=\mathrm{r}_{0}} \cong \frac{\mathrm{U}}{\mathrm{r}_{\mathrm{o}}}$

where 


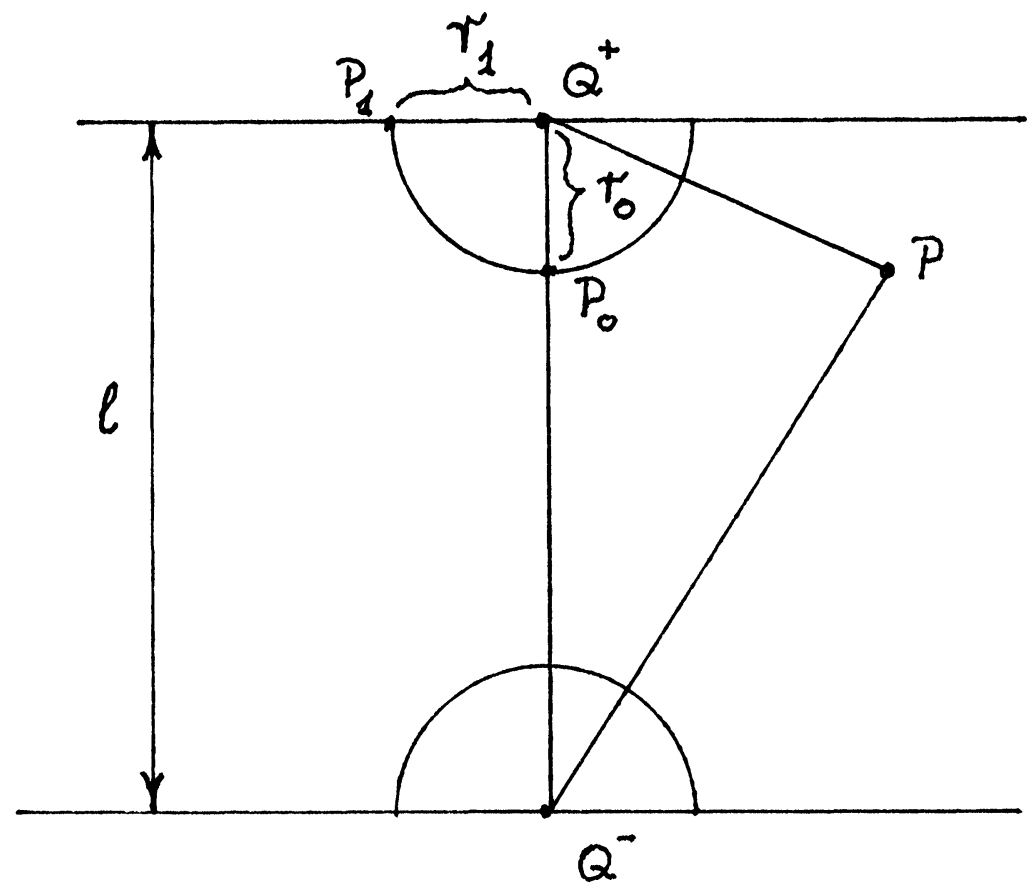

FIGURE 3 The position of spherical centres $\mathrm{Q}^{+}, \mathrm{Q}^{-}$

$\mathrm{U}=\mathrm{U}\left(\mathrm{P}_{\mathrm{o}}\right)=\frac{\mathrm{Q}}{4 \pi \varepsilon_{\mathrm{si}}}\left(\frac{1}{\mathrm{r}_{\mathrm{o}}}-\frac{1}{1-\mathrm{r}_{\mathrm{o}}}\right)$

The total current is thus:

$\mathscr{T}=\int_{(\mathrm{A})} \mathrm{jdA}=2 \mathrm{r}_{\mathrm{o}}^{2} \pi \frac{1}{\rho} \frac{\mathrm{U}\left(\mathrm{P}_{\mathrm{o}}\right)}{\mathrm{r}_{\mathrm{o}}}$

Since the potential difference between two equipotential surfaces $a$ and $b$ is $2 \mathrm{U}\left(\mathrm{P}_{\mathrm{o}}\right)$, the resistance $\mathrm{R}_{\mathrm{e}}$ can be calculated as:

$$
\mathrm{R}_{\mathrm{e}}=\frac{2 \mathrm{U}\left(\mathrm{P}_{\mathrm{o}}\right)}{\mathscr{T}}=\frac{\rho}{\mathrm{r}_{\mathrm{o}} \pi}
$$




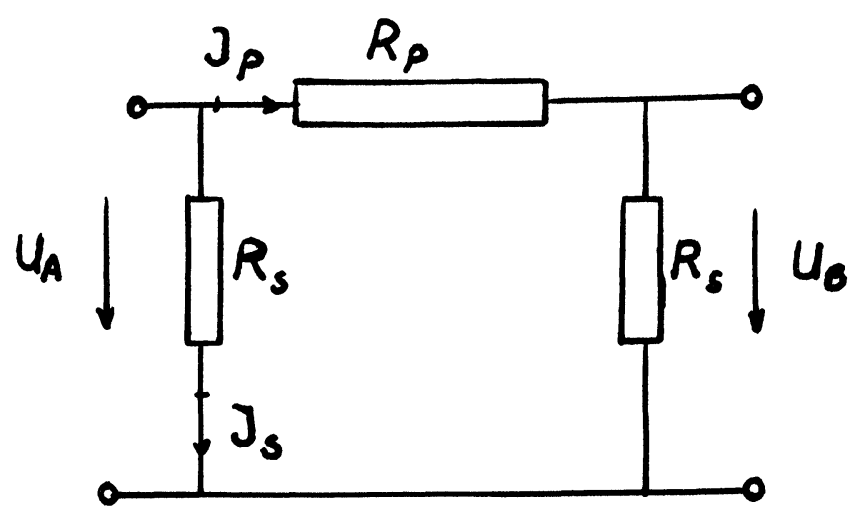

FIGURE 4 The equivalent circuit

From the equality of the hemisphere surface with the $n-n^{+}$junction one, the value $r_{o}$ can be calculated.

$r_{o}=\left[\frac{\pi D h}{4}+h^{2}+\frac{D^{2}}{8}\right]^{1 / 2}$

When the structure of Fig. 1 was replaced by the one in Fig. 2, an important structural simplification was made, because the whole current $J$ was supposed to cross the electrode $C$. This means that with respect to the equivalent circuit in Fig. 4 that only the current conducting element $R_{s}$ is taken into consideration. Thus the resistance $R_{e}$ given by 1.5 is the resultant of two serial connected $R_{s}$ resistances.

$\mathrm{R}_{\mathrm{s}}=\frac{\mathrm{R}_{\mathrm{e}}}{2}=\frac{\rho}{2 \mathrm{r}_{\mathrm{o}} \pi}$

It can be seen from Fig. 1 that there is an other current component $\mathscr{T}_{\mathrm{p}}$ which flows directly between the layers $a, b$. The resistance which represents this current conduction in the equivalent circuit, is $R_{p}$. This can be calculated on one side from the circuit given in Fig. 4, and by using the expression of potential 1.1 on the other.

$$
\mathrm{U}_{\mathrm{B}}=\mathrm{U}_{\mathrm{A}} \frac{R_{\mathrm{s}}}{\mathrm{R}_{\mathrm{p}}+\mathrm{R}_{\mathrm{s}}}=\frac{\mathrm{Q}}{4 \cdot \pi \cdot \varepsilon_{\mathrm{si}}}\left(\frac{1}{\mathrm{r}_{\mathrm{t}}}-\frac{1}{\left[\ell^{2}+\mathrm{r}_{\mathrm{t}}^{2}\right]^{1 / 2}}\right)
$$


where $U_{A}$ is equal to $U\left(P_{o}\right)$, with $P_{o}$ being the potential of the equipotential surface a, given by equation 1.3 .

For $R_{p}$ the following expression can be given:

$$
\begin{aligned}
\mathrm{R}_{\mathrm{p}}=\frac{\rho}{2 \cdot \mathrm{r}_{\mathrm{o}} \cdot \pi}\left\{\left[\frac{\frac{\mathrm{r}_{\mathrm{t}}}{\mathrm{r}_{\mathrm{o}}}-\frac{\mathrm{r}_{\mathrm{t}}}{\ell-\mathrm{r}_{\mathrm{o}}}}{1-\left[\left(\frac{\ell}{\mathrm{r}_{\mathrm{t}}}\right)^{2}-1\right]^{-1}}\right]-1\right\} & \int_{\rho} \\
& =\frac{\rho}{2 \cdot \mathrm{r}_{\mathrm{o}} \cdot \pi}\{\varphi-1\}
\end{aligned}
$$

The expression for $\varphi$ is given by the one in the brackets. The resistance of the SRTS can be measured between the points A, B. It can be called $R_{A B}$ and is given by

$\mathrm{R}_{\mathrm{AB}}=\beta \frac{\rho}{\mathrm{r}_{\mathrm{o}} \pi} \frac{\varphi-1}{\varphi+1}$

The term $\beta$ expresses the effect of simplifications used in deriving equation 1.9. Its value can be determined by comparing the calculated and measured results.

\section{THE TEMPERATURE DEPENDENCE OF RESISTIVITY}

For the calculation of this dependence the method described by $\mathrm{Li}$ and Turber ${ }^{4}$ is used. This method is based on the assumption that the current conduction of minority carriers can be neglected. This assumption if fulfilled fairly well in the temperature range $200<\mathrm{T}<400 \mathrm{~K}$ and for the doping concentration range, $2 \cdot 10^{15}>\mathrm{N}_{\mathrm{D}}>1 \cdot 10^{14} \mathrm{~cm}^{-3}$ which is the range of interest in our case.

$\rho^{-1}=q \cdot \mu_{n} \cdot n$

In this expression $\mu_{n}$ is the mobility, $n$ is the concentration of electrons; 
both are temperature dependent. For the calculation of electron concentration, the local neutrality of the semiconductor is considered. $n=N_{D}^{+}$, where $\mathrm{N}_{\mathrm{D}}^{+}$is the concentration of ionized donors, representing a function of Fermi level $E_{F}$ and donor level $E_{D}$.

$\mathrm{N}_{\mathrm{D}}^{+}=\frac{\mathrm{N}_{\mathrm{D}}}{1+2 \exp \left[\left(\mathrm{E}_{\mathrm{F}}-\mathrm{E}_{\mathrm{D}}\right) / \mathrm{kT}\right]}$

For the electron concentration the following relation can be given:

$\mathrm{n}=\frac{\mathrm{N}_{\mathrm{c}}}{\exp \left[\left(\mathrm{E}_{\mathrm{c}}-\mathrm{E}_{\mathrm{F}}\right) / \mathrm{kT}\right]+0.27}$

where $\mathrm{N}_{\mathrm{c}}$ is the density of states in the conduction band. By using the expression given in (4), and taking into consideration the known physical constants, one obtains:

$\mathrm{N}_{\mathrm{c}}=6,17 \cdot 10^{15} \cdot \mathrm{T}^{3 / 2} \mathrm{~cm}^{-3}$

$\mathrm{n}$ can be calculated from equ. 2.2, 2.3, 2.4. For small $\mathrm{N}_{\mathrm{D}} / \mathrm{N}_{\mathrm{C}}$ values, which is a fairly good assumption for the given $N_{D}$ range, $n$ can be approximated by:

$\mathrm{n}=\frac{\mathrm{N}_{\mathrm{D}}}{1+\frac{\mathrm{N}_{\mathrm{D}}}{N_{c}} 2 \mathrm{e} \frac{\mathrm{E}_{\mathrm{c}}-\mathrm{E}_{\mathrm{D}}}{\mathrm{kT}}}$

If phosphorus is used as n-type dopant material, $E_{C}-E_{D}-0,044 \mathrm{eV}$.

For the calculation of mobility the assumption was made that electron scattering is caused by only two processes, the lattice scattering $\mu_{\mathrm{L}}$, and the scattering on ionized donor atoms $\mu_{\mathrm{I}}$. This is a good assumption for the given concentration and temperature range. In this case $\mu_{n}$ can be expressed as follows:

$\mu_{n}=\mu_{L}\left[1+x^{2}\left\{c_{i}(x) \cos x+\sin x \cdot\left(s_{i}(x)-\frac{\pi}{2}\right)\right\}\right]$

where $C_{i}(x)$ and $S_{i}(x)$ are functions called integral cosine and integral sine respectively, and $x^{2}=6 \mu_{L} / \mu_{I}$. The value of $\mu_{L}$ is given in Table I. 
TABLE I

Lattice scattering, $\mu_{L}$ as a function of temperature

\begin{tabular}{lrrrrrr}
\hline $\mathrm{T}(\mathrm{K})$ & 200 & 250 & 300 & 350 & 400 & 500 \\
$\mu_{L}\left(\mathrm{~cm}^{2} / \mathrm{Vsec}\right)$ & 3730 & 2180 & 1430 & 1010 & 748 & 479 \\
\hline
\end{tabular}

When examining graphically the plot $\mu_{\mathrm{L}}(\mathrm{T})$, one can conclude that this function has a form as follows:

$\mu_{\mathrm{L}}=\mathrm{a}\left(\frac{1}{\mathrm{~T}}\right)^{\mathrm{c}}+\mathrm{b}(\mathrm{T}-292)$

The constants a,b,c are determined so that for temperature values 200 , $300,400 \mathrm{~K}, 2.7$ gives the same result as in the table. However for intermediate temperatures and at $\mathrm{T}=500 \mathrm{~K}$ the difference is smaller than $0,5 \%$.

These values are as follows:

$\mathrm{a}=1,1516 \cdot 10^{9}, \mathrm{~b}=0,2678, \mathrm{c}=2,3845$.

This ionized donor scattering has also been given in (4). This expression applied to our case can be written according to the following:

$\mu_{\mathrm{I}}=\frac{7,3 \cdot 10^{17} \cdot \mathrm{T}^{1,5}}{\mathrm{~N}_{\mathrm{D}} \cdot \ln \left(1,1806 \cdot 10^{20} \cdot \mathrm{T}^{2} / \mathrm{n}+1\right)}$

Equations 2.1-2.8 give the value of specific resistance as a function of $\mathrm{T}$. By using this result, the value of $\rho$ can be calculated. These results are given in Table II, where $\rho\left(20^{\circ} \mathrm{C}\right)=5 \Omega \mathrm{cm}$. The value of $\rho$ is calculated for a given doping concentration, for temperatures $\mathrm{T}=293 \mathrm{~K}, 313 \mathrm{~K}, 333 \mathrm{~K}$ and the experimental function 2.9 is determined matching the calculated

TABLE II

Resistivity ratio, $\rho(\mathrm{T}) / \rho\left(20^{\circ} \mathrm{C}\right)$, as a function of temperature

\begin{tabular}{rccc}
\hline $\mathrm{T}\left({ }^{\circ} \mathrm{C}\right)$ & $\rho(\mathrm{T}) / \rho\left(20^{\circ} \mathrm{C}\right)$ & $\mathrm{T}\left({ }^{\circ} \mathrm{C}\right)$ & $\rho(\mathrm{T}) / \rho\left(20^{\circ} \mathrm{C}\right)$ \\
\hline-40 & 0,5927 & 30 & 1,0800 \\
-30 & 0,6516 & 40 & 1,1634 \\
-20 & 0,7142 & 50 & 1,2500 \\
-10 & 0,7803 & 60 & 1,3395 \\
0 & 0,8501 & 70 & 1,4321 \\
10 & 0,9233 & 80 & 1,5276 \\
20 & 1 & 90 & 1,6257 \\
\hline
\end{tabular}




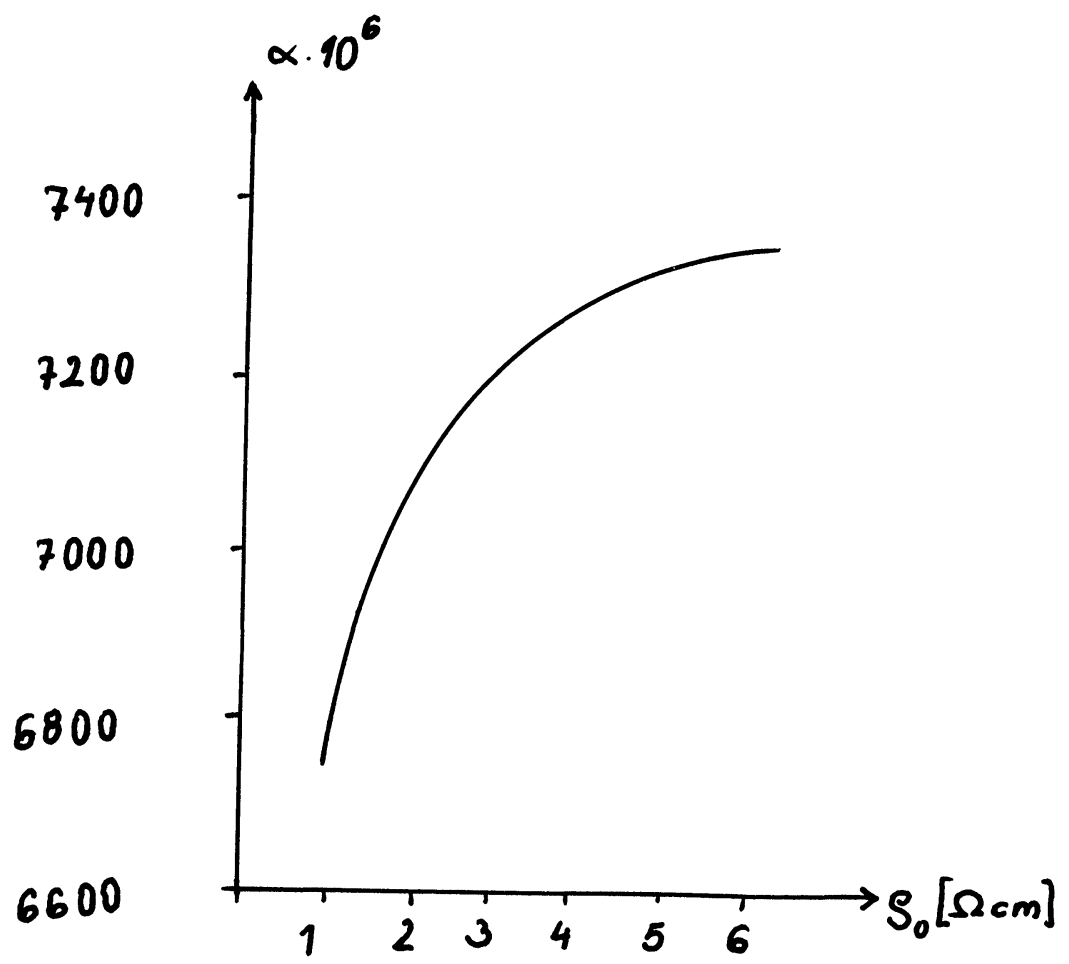

FIGURE 5 The calculated $\alpha\left(\rho_{\mathrm{o}}\right)$ function

results with maximum accuracy, by using the root mean square method (where $\mathrm{T}_{\mathrm{o}}=293 \mathrm{~K}$ and $\rho_{\mathrm{o}}=\rho\left(\mathrm{T}_{\mathrm{o}}\right)$ ).

$\rho=\rho_{\mathrm{o}} \cdot \exp \left[\alpha \cdot\left(\mathrm{T}-\mathrm{T}_{\mathrm{o}}\right)\right]$

By this method an $\alpha\left(\rho_{\mathrm{o}}\right)$ function can be calculated which is illustrated in Fig. 5.

\section{THE COMPARISON OF MEASUREMENT RESULTS WITH THE THEORY}

In the course of this examination, the value of $\beta$ in equation 1.9 is determined. For this purpose, the structure of Fig. 1 was realized with the 


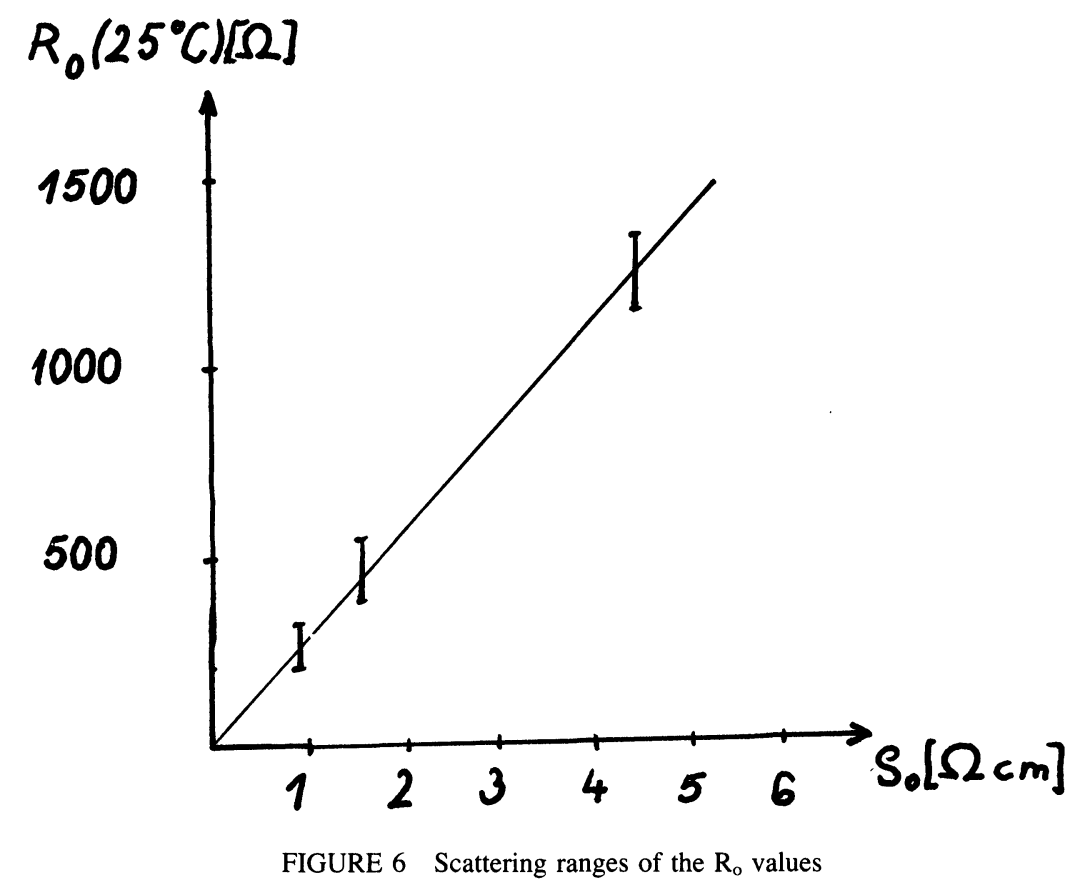

following geometry parameters: $r_{t}=100 \mu \mathrm{m}, \mathrm{D}=24,5 \mu \mathrm{m}, \mathrm{h}=1,8$ $\mu \mathrm{m}, 1=940 \mu \mathrm{m}$, on silicon slices of different specific resistance $(\rho)$ values. The sensor elements were measured for temperatures $\mathrm{T}=293 \mathrm{~K}$, $313 \mathrm{~K}, 333 \mathrm{~K}$, and the approximating exponential functions of equation 2.9 were determined, by using the same method mentioned earlier. The $R_{o}$ values resulted from this examinations, and its scattering ranges are illustrated in Fig. 6. The averaged value of $R_{o}$ is compared to the calculated result of equ. 1.9 and a $\beta=1.1$ value is determined.

The theoretical and measured $\alpha$ values are also compared. Their averaged values and scattering ranges are given in Fig. 5 in case of different $\rho$ values. It can be seen that a good fit with a relative small scattering range resulted. This comes from the fact that for the given doping concentration $\alpha$ varies only weakly with $N_{D}$.

Calculated results and measurements are compared for a wider temperature range, as well. For this investigation semiconductor slices of 


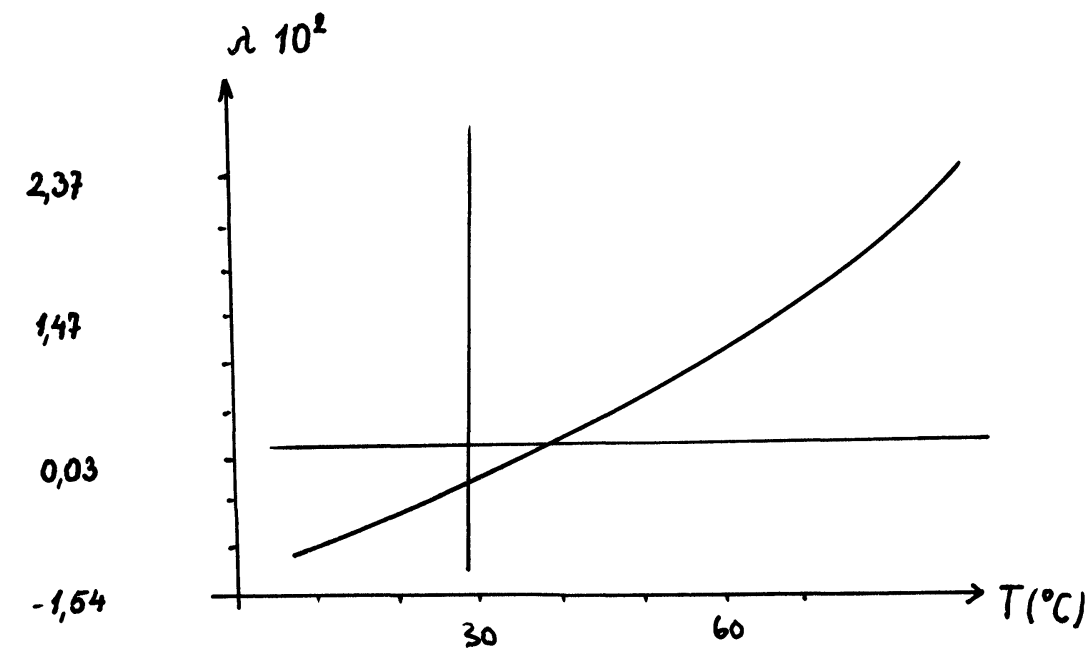

FIGURE 7 The $\lambda(\mathrm{T})$ function

$\rho\left(25^{\circ} \mathrm{C}\right)=6 \Omega \mathrm{cm}$ where used. The temperature range was $-50<\mathrm{T}<100^{\circ} \mathrm{C}$. $\lambda$ was evaluated for:

$\lambda(\mathrm{T})=\frac{\mathrm{R}_{\text {meas }} / \rho_{\text {calc. }}(\mathrm{T})}{\mathrm{R}_{\text {meas }} / \rho_{\text {calc. }}\left(25^{\circ} \mathrm{C}\right)}-1$

$\lambda(\mathrm{T})=0$ gives the case of exact fit of measurements with calculation. Fig. 7 shows the $\lambda(\mathrm{T})$ function. The resistance was measured in $10^{\circ} \mathrm{C}$ steps, and the results of 30 samples were averaged in the value of $\lambda$. It can be seen the error is smaller than $2 \%$ in the greater part of the temperature range. For higher temperatures $\lambda$ increases which is possibly the result of a physical effect which has not been considered.

\section{SUMMARY}

A simple physical model has been developed to calculate the effect of geometry. An expression has been determined to calculate the electrical resistance of an SRTS element of given geometry and doping concentration. 
Based on results given in the literature, a computational method has been worked out to calculate the temperature and doping concentration dependence of specific resistivity $\rho\left(T, N_{D}\right)$, in the case of phosphorus as the dopant material. Measurements were carried out and the results compared to calculations. A good fit could be achieved.

\section{REFERENCES}

1. M. Beitner, G. Tomasi: Mikroelektronischer Spreading-Widerstand-Temperatursensor Siemens Forsch.-n. Entwickl.-Ber.Bd lo Nr.2,S 65-71. 1981

2. A. Petersen: Silicon Temperature Sensors. Electronic Components and Applications, 5 No. 4. pp 206-213. Sept. 1983

3. A. Reaber, Dr.-Ing.: A Silicon Spreading Resistance Sensor for Temperatures from $-50^{\circ} \mathrm{C}$ up to $350^{\circ} \mathrm{C}$. Proc. European Solid State Devices Research Conference (ESSDERC'81), Toulouse-France, Sept. 14-17, 1981

4. S.S.li, W.R. Thurber: The Dopant Density and Temperature Dependence of Electron Mobility and Resistivity in n type Silicon Solid State Electronics 20, pp. 609-616, 1977 

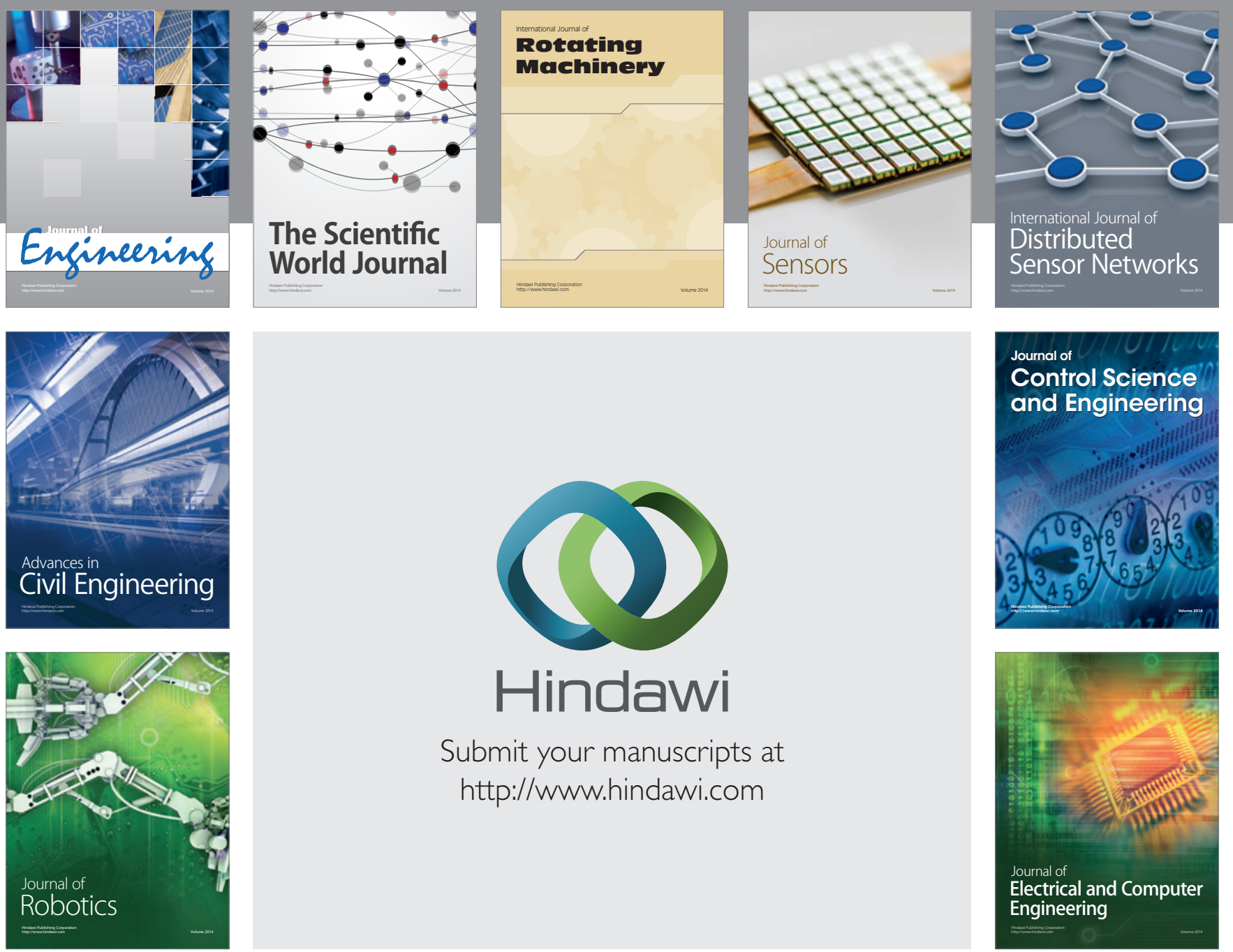

Submit your manuscripts at

http://www.hindawi.com
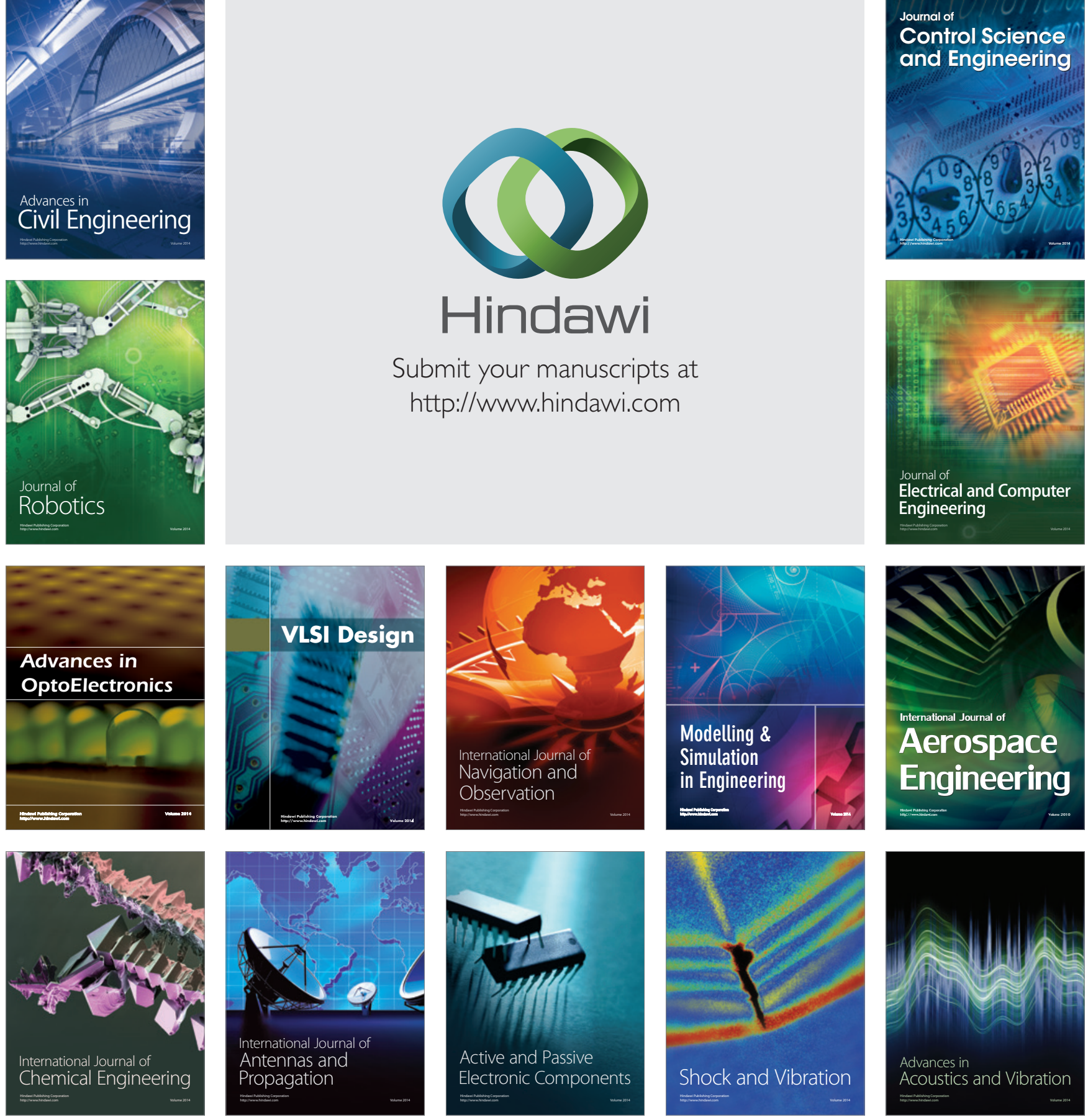